\title{
A prevenção da violência contra a criança na experiência do Ambulatório de Atendimento à Família: entraves e possibilidades de atuação
}

\author{
The prevention of violence against children \\ in the experience of the "outpatient family clinic": \\ problems and possibilities of action
}

Ana Lúcia Ferreira 1

Hebe Signorini Gonçalves 1

Mário José Ventura Marques 1

Sylvia Regina de Souza Moraes 1

\footnotetext{
${ }^{1}$ Instituto de Puericultura e Pediatria Martagão Gesteira, Departamento de Pediatria, 3o andar, Universidade Federal do Rio de Janeiro. Av. Brigadeiro Trompowsky, s/no, Ilha do Fundão, Cidade Universitária, Rio de Janeiro, RJ, 21941-590, Brasil. anaferr@gbl.com.br
}

\begin{abstract}
This paper is based upon the experience of a multidisciplinary team of health professionals of the Instituto de Puericultura e Pediatria Martagão Gesteira - the pediatric hospital of the Federal University of Rio de Janeiro. It reports some of the aspects related to the complexity of a hospital-based approach to children victims of violence and their families. The objective of this article is to discuss some of the issues involved in the target public characterization, in the way families deal with violence and in how they report such conditions to health services. The limitations of such practice by the multidisciplinary team are also presented. The influence of family's social conditions in the follow-up of those children and some aspects related to the report of cases to child protection agencies are also considered. On such basis, the authors discuss some of the proceedings adopted by the "Outpatient Family Clinics" that are accounted for tertiary prevention of violence against children.
\end{abstract}

Key words Violence; Child; Outpatient Care; Prevention
Resumo $O$ artigo apresenta alguns aspectos relacionados à complexidade do atendimento às crianças vítimas de violência e suas famílias a partir do trabalho desenvolvido pelo Ambulatório de Atendimento à Família do Instituto de Puericultura e Pediatria Martagão Gesteira, hospital pediátrico da Universidade Federal do Rio de Janeiro. O objetivo do trabalho é discutir questões relacionadas à definição da clientela atendida, à forma como as famílias trazem o problema e lidam com a violência e à limitação da atuação da equipe interdisciplinar. São também abordadas a interferência de aspectos sociais no acompanhamento dos casos e alguns aspectos da notificação aos conselhos tutelares. À luz dos problemas discutidos, os autores relatam os procedimentos adotados no Ambulatório, que representam formas de atuação no nível de prevenção terciária da violência contra as crianças.

Palavras-chave Violência; Criança; Assistência Ambulatorial; Prevenção 


\section{Introdução}

A preocupação com a violência contra a criança, suas várias formas de apresentação e as estratégias para combatê-la têm sido mais claramente identificadas neste século, especialmente a partir dos anos 60 quando o tema dos Direitos Humanos e dos Direitos da Criança passou a integrar a agenda internacional. Embora seja um fenômeno muito estudado, é ainda pouco conhecido. Trata-se de um tema complexo, principalmente por sua múltipla determinação. Segundo Belsky (1993), a violência é resultado de fatores vinculados ao agressor e à criança individualmente, à família, à comunidade e à sociedade ou cultura. A compreensão desses fatores é necessária para fundamentar e implementar estratégias de prevenção e de intervenção precoce.

A prevenção da violência pode ser trabalhada em três níveis: o nível primário, que tem como alvo a população em geral, atuando através de intervenções que educam, promovem a competência social, incentivam mudanças e ampliam as redes sociais; o secundário, dirigido a grupos que se considera serem de alto risco; e o terciário, em que a prevenção é instituída após ter ocorrido uma condição de abuso, e cujas ações visam a reduzir seqüelas e a evitar reincidências (Harrington \& Dubowitz, 1993).

Diversos autores enfatizam a importância do setor saúde como promotor e mediador de ações cujo impacto pode vir a contribuir de forma importante na atenuação da violência. Elliot (1993) sugere que os programas de prevenção da violência sejam desenvolvidos aproveitando-se as oportunidades em que as pessoas têm necessidade de procurar os serviços de saúde. Sendo assim, o pré-natal, os momentos em torno do parto, as consultas de puericultura e o atendimento a agravos comuns da infância, e as consultas periódicas de adolescentes, adultos e idosos se constituem em chances de abordagem e discussão do tema "violência" como um possível elemento presente na vida das pessoas e co-responsável por condições que venham a comprometer o seu bem-estar físico ou mental. Essas oportunidades permitem o estabelecimento de vínculos entre a família e os profissionais da área, criando condições favoráveis para a identificação precoce e o manejo dos casos.

Segundo a Organização Pan-Americana da Saúde, o setor saúde constitui a encruzilhada para onde confluem todos os corolários da vio- lência (Minayo, 1994). De fato, as conseqüências físicas e emocionais fazem com que as vítimas recorram, com freqüência, aos serviços de saúde, que precisam responder a esta demanda.

O Instituto de Puericultura e Pediatria Martagão Gesteira (IPPMG), hospital pediátrico da Universidade Federal do Rio de Janeiro, criou em 1995 o Núcleo de Atenção às Crianças Vítimas de Violência, e vem atuando nessa área com atividades de ensino, pesquisa e assistência. Tomada como produto de múltiplos fatores, a violência contra a criança requer uma ação interdisciplinar e interinstitucional, e é nessa perspectiva que se coloca a proposta do Núcleo.

O componente assistencial é desenvolvido pelo Ambulatório de Atendimento à Família (AAF). A escolha deste nome reflete uma proposta de trabalho que tem por base o entendimento de que a abordagem da dinâmica das relações familiares é essencial para interferir no processo de violência instalado contra a criança, uma vez que permite entender de forma mais global as causas e as conseqüências do abuso. Além disso, uma denominação que não explicita a violência pode evitar a estigmatização dessas crianças e suas famílias.

O AAF iniciou suas atividades em 1996, e desde então atendeu a cerca de 200 crianças. $\mathrm{O}$ atendimento é feito por equipe constituída por duas pediatras, uma enfermeira, uma psicóloga e um assistente social. A proposta de trabalho da equipe é identificar, acompanhar e prevenir recorrências em casos de violência contra a criança e o adolescente, caracterizando, portanto, uma ação preventiva de nível terciário. Ao prestar atendimento às vítimas de violência numa unidade hospitalar, inúmeras são as dificuldades enfrentadas, e estas têmnos obrigado a repensar os próprios limites de atuação do setor saúde nesta abordagem. O objetivo deste artigo é discutir alguns aspectos do atendimento hospitalar a casos de violência contra a criança, e discutir as possibilidades de intervenção e prevenção da violência à luz da experiência adquirida na prática do AAF.

\section{O ambulatório de atendimento à família: entraves e possibilidades de atuação}

A equipe do AAF entende que para tratar da violência na família é preciso adotar uma abordagem que alguns autores qualificam como 
empática (Gelles, 1997). Essa abordagem, longe de significar o endosso ou a diminuição da responsabilidade do agressor, busca entender o ato violento como resultado de elementos associados à dinâmica das relações intra e extrafamiliares. Adotar esse princípio como referência significa que não se pode tratar de modo pontual a agressão identificada, por mais grave que ela seja; ao contrário, a violência contra a criança é vista como um sintoma e pedido de socorro que a família, como um todo, envia à sociedade. Assim, a equipe busca identificar e auxiliar outros membros que possam estar envolvidos numa relação difícil e conflituosa, contribuindo para a compreensão da dinâmica familiar. A criança identificada como vítima de violência é, portanto, o caso-índice a partir do qual são trabalhados os conflitos familiares.

As concepções de "violência" e de "vítima" adotadas no AAF são tomadas em toda a sua amplitude e complexidade. Além disso, fenômenos próprios da dinâmica familiar são levados em consideração durante todo o processo de atendimento. Ao colocar em prática essa proposta, encontramos alguns obstáculos ao desenvolvimento de um trabalho de prevenção terciária, que são apresentados e discutidos a seguir.

\section{A dificuldade de definição da clientela}

A identificação dos casos é uma estratégia fundamental no combate à violência contra a criança, já que cria a possibilidade da prevenção terciária. Com o objetivo de sensibilizar os profissionais do IPPMG em relação a esta questão, e com o objetivo de ampliar a detecção dos casos, foi realizado logo após o início das atividades do AAF um treinamento cujo público alvo eram funcionários escolhidos por sua inserção em setores estratégicos. Médicos, psicólogos, enfermeiros, assistentes sociais e pessoal de apoio com atividades nas enfermarias, emergência, ambulatórios e setor de triagem tomaram contato com a temática da violência, sendo instruídos para identificar sinais de sua ocorrência.

O AAF conheceu, desde então, um crescimento importante na demanda interna, alimentada pelos encaminhamentos que têm origem nos setores treinados para o reconhecimento precoce da violência. Essa atenção diferenciada, e difundida em toda a unidade hos- pitalar, tem tido três conseqüências. Em primeiro lugar, tem permitido que todos os serviços se comprometam com o tema, e saibam para onde encaminhar os casos detectados. Em segundo lugar, tem proporcionado uma mudança na qualidade do conjunto dos serviços hospitalares prestados, pois vem reforçando, no contato entre os profissionais e a clientela, a necessidade de se tomar em consideração fatores do relacionamento familiar que podem contribuir para o desencadeamento de algumas manifestações clínicas de seus pacientes. Em terceiro lugar, tem ampliado em muito as possibilidades da prevenção terciária, já que capta a clientela que será efetivamente acompanhada no AAF.

Com a criação do AAF, grande número de situações que sempre estiveram presentes no dia-a-dia da prática hospitalar passou a ser nomeado como "violência", sendo essas situações hoje referidas ao serviço. Como exemplo, temos pacientes crônicos considerados vítimas de negligência devido à não-adesão ao tratamento proposto (falta às consultas, não-utilização da medicação prescrita, etc.); negligência associada a problemas socioeconômicos graves; e problemas familiares os mais diversos, antes encaminhados ao serviço de Psicologia e agora vistos como abuso psicológico. Essa clientela tem sido encaminhada ao AAF, o que tem suscitado discussão sobre sua elegibilidade para o acompanhamento no Ambulatório.

A equipe tem atualmente uma certa dificuldade em definir com clareza quais crianças precisam de acompanhamento no serviço. Quem deve ser cliente de um ambulatório que se propõe a acompanhar vítimas de violência? Obviamente, casos clássicos não suscitam dúvidas. Outros, no entanto, acreditamos pudessem ser mantidos em acompanhamento em outro setor, sob a supervisão da equipe do AAF, desde que o médico responsável adotasse uma nova abordagem no atendimento pediátrico, e desde que houvesse maior envolvimento com as áreas de Psicologia e Serviço Social.

Por se tratar de uma fase de transição na qual os procedimentos de diagnóstico e de intervenção vêm sendo aprimorados, todas as crianças encaminhadas têm sido, em princípio, admitidas para atendimento até que a Instituição, como um todo (incluindo o próprio AAF), consiga estabelecer com clareza a partir de que grau de severidade e suspeição há necessidade de encaminhamento para uma atenção especializada. 


\section{A forma como o caso se apresenta à equipe do $\mathrm{AAF}$}

Um dos aspectos mais delicados do atendimento às famílias envolvidas com alguma forma de violência diz respeito à abordagem do tema pelos profissionais do AAF, de forma a garantir o acompanhamento adequado e a implementação de medidas eficazes para a atenuação ou resolução da violência. Esta aproximação depende diretamente da forma como o problema da violência chega ao ambulatório. Neste sentido, identificamos duas situações:

1) Há crianças que são trazidas ao IPPMG com a intenção de resolver problemas diretamente relacionados à violência, sendo referidas ao AAF. Nestes casos, o tema é tratado de forma mais objetiva, o que facilita o diálogo, o encaminhamento e os desdobramentos do atendimento. No entanto, o fato de a criança ser trazida por uma pessoa que revele a violência não garante necessariamente proteção ou acompanhamento. Quando essa pessoa faz parte do núcleo familiar, freqüentemente está implicada na dinâmica que gera a violência. Sendo assim, é preciso que a equipe proceda com muita cautela para não eleger como "bom" o indivíduo que trouxe a criança e fez a denúncia, tratando por extensão como "mau" aquele que é o autor do abuso, contribuindo assim para perpetuar a dinâmica das relações familiares que está na raiz da violência. Segundo Cirillo e Di Blasio (1991), os papéis de "bom" e "mau" se alternam para sustentar a violência, e é preciso grande habilidade para estabelecer vínculos com o elemento protetor, sem tratá-lo como único veículo de mudança e reversão do processo que produz a violência. Como forma de superar esse problema, tentamos trazer outros familiares ao acompanhamento.

Quando a criança é trazida por alguém que não faz parte da família, essa pessoa geralmente não está implicada na dinâmica familiar, mas, por outro lado, pode não ter condições de interferir nessa dinâmica, o que limita suas possibilidades de proteger a criança. Nessas situações, buscamos sempre identificar e envolver um membro da família que possa ter um papel mais efetivo na proteção da criança.

2) Há crianças que são trazidas ao hospital por outros motivos, e os profissionais responsáveis pelo atendimento inicial suspeitam ou verificam que está ocorrendo algum tipo de vio- lência, encaminhando-as ao AAF. Nesses casos, o tema da violência nem sempre é tratado diretamente nas primeiras consultas, mas desde o primeiro contato a equipe explicita os objetivos do atendimento oferecido pelo AAF e a intenção de abordar as relações familiares. $\mathrm{Na}$ primeira oportunidade, o tema da violência é colocado em discussão. A receptividade da família a essa abordagem tem grande influência sobre a adesão ao acompanhamento. As diferenças entre os propósitos da equipe e a demanda familiar suscitam um conflito básico: a família não está esperando receber especificamente este tratamento, mas a equipe considera fundamental intervir na dinâmica familiar, objetivando a proteção da criança e evitando seqüelas futuras.

Percebe-se que a abordagem inicial é um momento crítico na construção do vínculo e do processo de acompanhamento. Nos casos acima descritos, o profissional precisa estar preparado para lidar com a violência (tema que mobiliza emoções e é carregado de preconceitos) num momento em que o vínculo ainda não está estabelecido, as formas de reação da família não são conhecidas, e ainda assim é preciso responder ao problema da criança.

\section{A forma como as famílias lidam com a violência}

Independentemente da abordagem inicial e do tipo e da severidade do abuso, a relação das famílias com o profissional varia conforme a violência seja intra ou extrafamiliar, e conforme o modo como a família lida com o abuso sofrido pela criança. Identificamos quatro situações principais, assim agrupadas:

1) A violência que atinge a criança tem um agressor externo à família, e esta busca o AAF explicitando a violência sofrida. A experiência tem mostrado que quando o agressor não faz parte do núcleo familiar a história de abuso é mais facilmente revelada, e é maior a possibilidade de prevenção de reincidência. No entanto, em alguns casos a família tende a acreditar que os agravos físicos são os únicos que merecem acompanhamento continuado, não reconhece as implicações decorrentes da violência no bem-estar da criança a médio e longo prazo e, uma vez solucionados os problemas mais agudos decorrentes da violência, considera que pode encerrar o atendimento deixando de se beneficiar do suporte psicoló- 
gico necessário. Isso representa um entrave ao acompanhamento. O exemplo mais típico desse grupo é o estupro: muitas vezes, após terem sido verificadas e tratadas as lesões orgânicas e realizados os exames laboratoriais, a família vê o AAF como uma forma de reviver a violência, e abandona o tratamento.

2) A violência contra a criança foi perpetrada por um membro da família, e esta tenta ocultá-la. Este grupo é de difícil abordagem, já que os propósitos do trabalho do AAF em revelar e discutir as dificuldades do núcleo familiar se opõem ao interesse imediato da família. Com freqüência, trata-se de explicitar um problema que naquele momento a família não quer discutir, seja por não querer expor suas dificuldades, seja por não estar sequer preparada para percebê-las. A proximidade do agressor faz com que a revelação seja mais dificilmente obtida, eleva o risco de reincidência, e a negação da violência implica todo o núcleo familiar; muitas vezes conivente com o agressor ou com a agressão. É necessário um trabalho com grande sensibilidade para estabelecer vínculos com a pessoa que traz a criança ao atendimento, de modo a construir um espaço de confiança em que o abuso possa ser revelado, a reincidência evitada e os efeitos sobre a saúde da criança reduzidos. Se a construção desse vínculo falha, o acompanhamento ambulatorial é interrompido ou torna-se irregular.

3) A violência contra a criança, perpetrada por um membro da família, é trazida como quei$x a$. Nesses casos, a pessoa que traz a criançaque pode ou não ser membro da família - expõe o agressor e se expõe, deflagrando a discussão de uma série de problemas até então restritos ao âmbito familiar, que são descortinados a partir da revelação da violência. Os conflitos decorrentes tendem a envolver toda a família, especialmente a vítima e o agressor, e repercutem também no indivíduo que trouxe a queixa. A ação da equipe deve fortalecer quem fez a denúncia, e deve proteger a criança nesta situação que é carregada de tensão.

4) A violência contra a criança foi perpetrada por um membro da família, e outro parente ou o próprio agressor chegam ao AAF sem identificar a ação como violenta. Neste grupo, as famílias em geral resistem em reconhecer que sua ação ou omissão seja qualificada como violenta. Os limites do trabalho da equipe e os riscos de reincidência são grandes, já que a violência é fruto de valores culturais próprios des- sas famílias, e as possibilidades de modificação desses valores são limitadas, especialmente no interior do setor saúde. Nesta situação incluem-se, especialmente, os casos em que o abuso físico é utilizado como recurso para "educar" ou "disciplinar".

Estas situações vão definir o grau de dificuldade de atuação da equipe, e, conseqüentemente, as chances de sucesso na abordagem da violência que vitimiza as crianças. Cabe salientar, no entanto, que a classificação acima não é estanque, pois a atitude das famílias é dinâmica e sujeita a mudanças, inclusive em decorrência da própria intervenção da equipe.

\section{O acompanhamento interdisciplinar}

A importância de um caso ser mantido em acompanhamento deve-se: (a) à necessidade de monitorar as reincidências; (b) à investigação diagnóstica mais prolongada nas situações em que não se apresentam definidas inicialmente, ou nas quais a obtenção de informações sobre a dinâmica familiar e sobre as circunstâncias em que ocorreu o abuso depende do estabelecimento de um forte vínculo entre a família e o profissional responsável; (c) à necessidade de promoção de mudanças na dinâmica familiar, o que pode vir a ser um processo de longa duração. Para lidar com aspectos tão diversos, é necessária a ação de uma equipe multidisciplinar.

Com o objetivo de prover uma assistência interdisciplinar, realiza-se semanalmente uma reunião na qual as estratégias de encaminhamento de cada caso são definidas a partir da avaliação coletiva das situações dos atendimentos. Nessas reuniões, cada profissional apresenta a visão de sua disciplina específica. No atendimento médico e no atendimento do assistente social, é possível aos profissionais oferecer uma resposta imediata às necessidades concretas da família. No primeiro, o exame físico e os cuidados com o estado de saúde da criança respondem diretamente a essa demanda, e constituem-se em razões para a adesão ao atendimento proposto. No segundo, as dificuldades financeiras da maioria da clientela atendida no IPPMG requerem a oferta de benefícios diretos (cesta básica, auxílio-transporte), ou indiretos (inserção dos filhos em escolas, creches ou serviços de saúde), o que faz com que o atendimento do assistente social seja bem aceito pelas famílias. 
Ao contrário do que ocorre nos atendimentos médico e de assistente social, o atendimento psicológico, embora indispensável à condução da quase totalidade dos casos, não oferece resposta imediata às necessidades concretas das famílias. Além disso, o atendimento psicológico exige engajamento mais direto, comparecimento semanal e participação ativa dos responsáveis na resolução das dificuldades familiares. Por essas razões, ele tem sido realizado de forma mais irregular, e com menor grau de adesão. A falta de serviços regionalizados de Psicologia na rede de saúde, o que facilitaria o acesso da clientela a esse tipo de atendimento, dificulta ainda mais a adesão ao acompanhamento psicológico e a execução de uma proposta interdisciplinar e interinstitucional.

O exercício da interdisciplinaridade é por si só complexo, e a mobilização que o tema da violência gera nos profissionais e nas famílias torna-o ainda mais difícil. Muitas são as situações em que as famílias, por diversos motivos, não mantêm vínculo com todos os profissionais cuja atuação seria necessária para o adequado atendimento a seu caso. A ação interdisciplinar fica assim comprometida pela falta do olhar daquele profissional específico. No entanto, esses casos são mantidos em atendimento, tentando-se suprir essa falta nas discussões semanais.

\section{Interferência de alguns aspectos sociais no acompanhamento}

A violência muitas vezes está associada a fatores que trazem dificuldades marcantes para a manutenção do atendimento, e têm sido motivo de desgaste importante pela frustração que gera nos responsáveis pelos atendimentos. Alcoolismo, uso de outras drogas e dificuldades financeiras têm sido detectados com freqüência na clientela do AAF. A identificação precoce de tais fatores tem papel fundamental no estabelecimento de estratégias que permitam maior êxito na abordagem dessas famílias.

Embora reconheçamos que esses problemas produzem tensão nas relações familiares e podem vir a agravar conflitos geradores de violência, requerem programas de intervenção mais globais, capazes de modificar a realidade de vida dessas famílias. Ações dessa natureza fogem ao escopo de uma unidade hos- pitalar. Nesses casos, a equipe do AAF ressente-se da ausência de uma parceria externa, em nível comunitário, que torne possível acompanhar a família com outros recursos além daqueles oferecidos no atendimento hospitalar. No AAF, só tem sido possível lidar com as conseqüências da drogadição e das dificuldades financeiras. De toda maneira, esses assuntos são discutidos com a família, que é orientada sobre as formas de lidar com questões, e de buscar os recursos institucionais e comunitários disponíveis.

\section{A notificação}

A notificação de casos de violência aos Conselhos Tutelares, obrigatória segundo o Estatuto da Criança e do Adolescente quando da sua identificação ou suspeita, tem importante interferência na dinâmica do atendimento às crianças e suas famílias. Tal procedimento busca estabelecer uma parceria que é fundamental na proteção à criança e no apoio à família, uma vez que o campo de ação dos Conselhos é diferente e mais amplo que o de uma unidade hospitalar, e têm maior grau de resolubilidade nas questões sociais e jurídicas que envolvem a violência contra a criança.

É importante compreender que a determinação final da ocorrência de um abuso é uma questão legal e requer envolvimento multiprofissional (Kini \& Lazoritz, 1998). O papel da equipe de saúde é determinar se existe uma suspeita razoável a partir da qual a equipe e a família tomam decisões que interferem diretamente com a criança. $\mathrm{O}$ impacto que essa interferência produz em todo o contexto familiar faz com que a notificação seja efetivada só a partir de suspeitas consistentes, ou quando da confirmação.

Alguns casos encaminhados ao AAF comportam graus muito diferentes em termos da força da suspeita: doenças sexualmente transmissíveis, corrimento vaginal, hematomas, acidentes e intoxicações, lesões anogenitais, distúrbios do sono, alterações de comportamento e atraso no calendário vacinal são situações que ilustram o amplo espectro de condições suspeitas de alguma forma de abuso. Elas requerem investigação acurada de forma a tornar a notificação minimamente consistente.

Além do grau de suspeição, outras condições relacionadas às situações de violência com as quais lidamos - tais como a gravidade do 
caso e a regularidade do comparecimento às primeiras consultas agendadas - são fatores que influenciam a escolha do melhor momento para efetivar a notificação. Deve ser enfatizado que os casos graves que possam implicar grave risco para a criança são notificados de imediato.

Consideramos que, idealmente, no momento da notificação a equipe já deve ter conseguido estabelecer um vínculo com a família que assegure o acompanhamento do caso, e possa assim também funcionar como suporte para as situações desencadeadas pela notificação. Salvo nos casos de abandono de acompanhamento, as notificações são feitas com o conhecimento da família, que é informada sobre o conteúdo do relatório enviado, do que constará o trabalho inicial do Conselho e das repercussões possíveis.

É importante destacar que, apesar das dificuldades, a notificação é fundamental para o acompanhamento dos casos, uma vez que a equipe passa a ter um parceiro para dividir as medidas a serem tomadas, e tem a quem recorrer em situações de risco que porventura surjam durante o acompanhamento. Além disso, a notificação contribui para fazer cessar ou diminuir a situação de abuso, uma vez que esta passa a ser também objeto de ação legal. As relações entre o AAF e os Conselhos Tutelares vêm sendo progressivamente construídas, superando dificuldades comuns a todas as instituições que atuam na área da violência contra a criança.

\section{Considerações finais}

$\mathrm{O}$ atendimento dos casos de violência foi uma realidade que se impôs ao Instituto de Puericultura e Pediatria Martagão Gesteira. A instituição precisou responder a essa demanda, apesar de todas as dificuldades referentes ao enfrentamento da violência em nível hospitalar. A inadequação do modelo médico - preponderante na assistência hospitalar - na resposta à questão da violência fica mais acentuada à medida que são precárias as estruturas essenciais de suporte, internas e externas. Ainda assim, a ação é possível e o trabalho vem nos permitindo atingir resultados concretos.

Muitas das dificuldades discutidas no artigo poderiam ser minimizadas se programas de prevenção terciária da violência contra a criança já estivessem estruturados e contas- sem com o apoio dos demais níveis de prevenção. No Ambulatório de Atendimento à Família, ressentimo-nos da falta de serviços com os quais pudéssemos dividir os encargos do atendimento aos casos. Para a prevenção primária e secundária, seria importante contar com ações em nível comunitário que viessem a modificar as condições geradoras da violência e permitissem a inserção da atuação hospitalar num contexto que trabalhasse o tema de forma global, contexto este ainda inexistente.

Cohen e Swift (1993) defendem que a ação que visa a minorar a violência deve estruturar-se numa rede de serviços, com ação coordenada a partir do poder público, de modo a integrar os vários níveis de atividade, evitar duplicidade de serviços e dimensionar os programas de acordo com a demanda real. A nosso ver, a construção dessa rede possibilitaria ampliar o alcance da ação interdisciplinar e atingir resultados muito mais eficazes. A intervenção na família para fazer cessar a violência envolve questões que dizem respeito a direitos públicos, individuais e da família. A efetiva conquista desses direitos é urgente e requer um compromisso coletivo. 


\section{Referências}

Belsky J 1993. Etiology of Child Maltreatment: A Developmental-Ecological Analysis. Psychological Bulletin 114(3): 413-434.

Cirillo S \& Di Blasio P 1991. Niños Maltratados: Diagnóstico y Terapia Familiar. Paidós, Buenos Ayres, $171 \mathrm{p}$.

Cohen L \& Swift S 1993. A Public Health Approach to the Violence Epidemic in the United States. Environment and Urbanization 5(2): 50-66.

Elliott B 1993. Prevention of violence. p.277-288. In Elliott B el al (editores). Primary care: clinics in office practice. W.B.Saunders Company. Philadelphia.
Gelles R 1997. Intimate Violence in Families. Sage Publications, California, 204p.

Harrington D \& Dubowitz H 1993. What Can Be Done to Prevent Child Maltreatment?. p. 258-280. In RL Hampton et al. (eds.) - Issues in Children's and Families' Lives. Vol I. Family Violence: Prevention and Treatment. Sage Publications, California.

Kini N \& Lazoritz S 1998. Evaluation for Possible Physical or Sexual Abuse. Pediatric Clinics of North America 45(1): 205-219.

Minayo MCS 1994. A Violência Social sob a Perspectiva da Saúde Pública. Cadernos de Saúde Pública 10(Supl. 1): 7-18. 